\title{
Fracture characterization of bonded composites: A comparative study
}

\author{
Naghdali Choupani ${ }^{a^{*}}$ and Ahmet Refah Torun ${ }^{b}$
}

${ }^{a}$ Department of Mechanical Engineering, Engineering Faculty, Adana Alparslan Türkeş Science and Technology University, Adana, Turkey ${ }^{b}$ Department of Aerospace Engineering, Adana Alparslan Türkeş Science and Technology University, Adana, Turkey

\begin{tabular}{l}
\hline A R T I C L E I N F O \\
\hline Article history: \\
Received 1 February 2021 \\
Accepted 6 August 2021 \\
Available online \\
6 August 2021 \\
\hline Keywords: \\
Bonded composites \\
Fracture characterization \\
Interfacial \\
Interlaminar \\
Cohesive
\end{tabular}

\begin{abstract}
A B S T R A C T
Bonded joints have important benefits over conventional joining techniques such as rivets, welding, bolts and nuts in structural applications, particularly for components prepared of composite or polymeric materials. Due to the involvement of many geometric, material and construction variables, and the complex fracture and mechanical modes offered in the bonded joints, a proper consideration of fracture behavior is required to fully achieve their benefits. The fractures in bonded joints are mainly of three types; interlaminar (delamination), adhesive (interfacial) and cohesive crack. For a particular defect, crack propagation may occur in the tensile (mode I), the shear (mode II), and the tear (mode III) and their combinations (mixed mode). This study deals with topics such as theories of bonded composite joints and repairs, finite element analysis and fracture-based analysis and tests of mixedmode cohesive, interfacial and interlaminar fracture mechanics. By employing geometrical factors extracted from finite element analysis and experimental results obtained from a modified Arcan test fixture, the mixed-mode cohesive, interfacial, and interlaminar fracture toughness are determined and fracture surfaces obtained are discussed.
\end{abstract}

\section{Introduction}

Bonded joints are currently used broadly to join metallic and composite components in several areas such as automobile and aerospace structures. In the automobile industries, they are practically used as elementary sealant materials or in non-critical secondary structures. The aerospace industries, and especially aircraft repairs, are examples of areas where the application of bonded joint has also mostly been limited to secondary non-critical structures such as aerodynamic fairings and wing panels (Fig. 1). There are two main options for repair of aircraft: bolted or riveted mechanically fastened repair and adhesively bonded repair with either metal or composite patches (Fig. 2). Mechanically fastened repairs have been performed for years and provide many advantages: (a) they are very simple and inexpensive to perform, (b) there is not a lot of specialized training involved with teaching maintainers the process, (c) all of the materials involved with repairs are inexpensive and easy to find in industry, (d) none of the materials have specific shelf lives or difficult storage criteria, (e) designing and applying a mechanically fastened patch doesn't require any specialized equipment, (f) there are no mismatch and galvanic corrosion (Tserpes 2020, Baker 1999, Galińska \& Galiński 2020, Yengejeh et al. 2020, Khajedezfouli et al. 2020). The major disadvantages of mechanically fastened repairs are: (a) they introduce numerous additional stress concentrations at fastener holes, (b) there is low patching efficiency and cannot patch cracks, (c) it is difficult to detect cracks under patch, (d) rapid crack growth on exit from patch, (e) a badly designed repair can actually cause the aircraft component to be worse off after the repair, (f) holes that must be drilled for mechanical fasteners increase the possibility of damaging internal components, $(\mathrm{g})$ there is a threat of fretting with a bad mechanical repair, (h) loss of rivets or bolts during flight creates the possibility for foreign object damage, (i) there is a danger of corrosion under patch.

\footnotetext{
* Corresponding author. Tel: +90 (322) 455 0000, Fax: +90 (322) 4550039

E-mail addresses: nchoupani@atu.edu.tr (N. Choupani) 


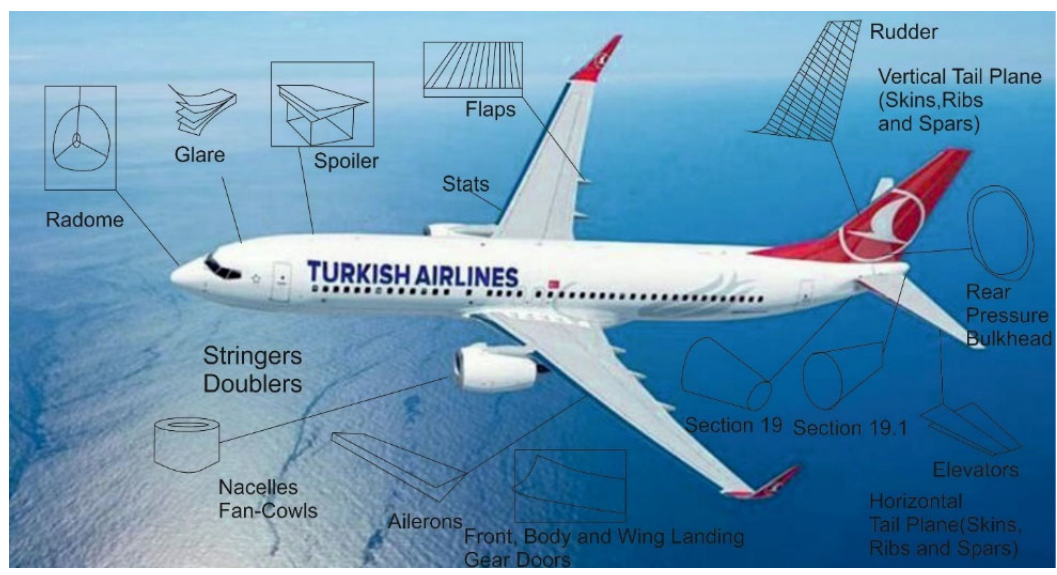

Fig. 1. Fuselage and wing of the aircraft are bonded structures

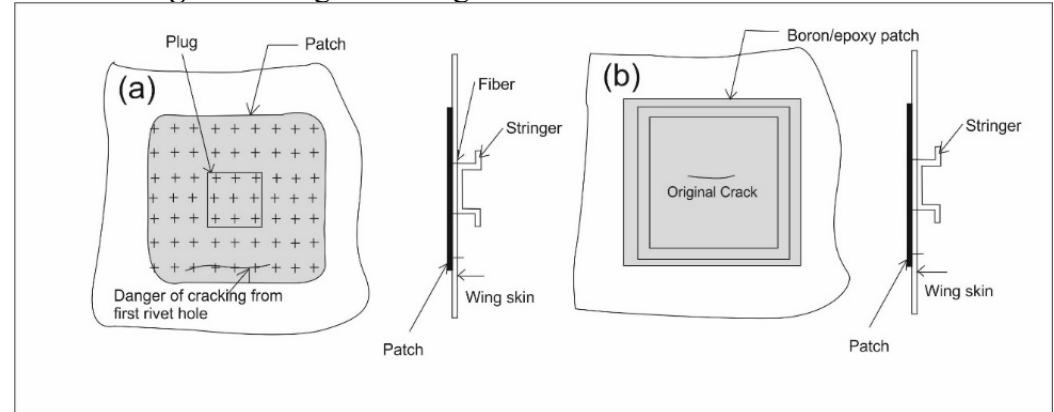

Fig. 2. Repair of aircraft; (a) mechanically fastened and (b) bonded composite repairs.

The advantages of using bonded joints and repair procedures over conventional mechanically fastened joints can be summarized as : (a) ability to bond dissimilar and damage-sensitive materials of different thickness, (b) fabrication of complex forms not possible by other fastening methods, (c) superior damping and vibration response control, (d) reduction in weight of critical structures through elimination of fasteners, because composite materials are much stronger and stiffer than metallic materials, patches can be made approximately three times thinner, (e) joint sealing protection, the technique of assembly also seals the joint (f) smoother external joint and aerodynamic surfaces, (g) improved fatigue strength, the adhesively bonded joint is fatigue resilient (h) economic and rapid assembly, adhesive bonding can simplify the production process and increase quality and reduce assembly cost (i) full load transfer and uniform stresses distribution over joined interfaces, adhesive bonding distributes stresses over the whole bonded region; therefore, stress concentrations are less likely to occur than in conventional fastening techniques, (j) galvanic corrosion reduction and prevention, the action of the adhesive provides corrosion resistance between the adherends (k) thermal and electrical insulation, (l) high reinforcing efficiency and ability to repair cracks without introducing open hole stress concentrations and new damage, no bolts or rivets are needed allowing maintainers to simply fix the area without further weakening of the structure and the ability to repair aircraft without introducing new damage is very desirable and (m) the use of adhesive joints does not require high temperatures such as welding or bracing, which improves the appearance of the joint and reduces its weight (Tserpes, 2020; Baker, 1999; Kinloch, 1987; Baldan, 2004; Higgins, 2000; Ducept et al., 2000; Santos \& Campilho, 2017; Aliha et al., 2021). In spite of bonded joint and repair increasing use and great potential, the use of them presents some limitations and inconveniences, particularly in critical and primary structural applications: (a) the joint cannot be disassembled simply and it is irreversible, which means that disassembly without damaging the structural components is not easy to achieve; assembly times may be greater than for alternative techniques, depending on the curing mechanism and elevated temperatures may be required, as well as particular fixtures; (b) adhesives are typically less resistant to chemical actions, and also are more vulnerable to aging than mechanical fastenings, (c) performing a bonded repair is more complicated than performing a bolted or riveted repair, some technical equipment is involved which requires specialized training, (d) field repairs are more difficult to perform because a lot of the materials, such as the adhesives and composites, need to be refrigerated and have short shelf lives, usually about six months, (e) there are some concerns with material compatibility; composite materials, such as boron/epoxy and graphite/epoxy, have lower coefficients of thermal expansion (CTE) than aluminium and this creates residual stresses in the repair that could possibly lead to stress corrosion cracking, (f) some composites, particularly graphite, can create galvanic corrosion problems when in direct contact with aluminium, $(\mathrm{g})$ there is no universal adhesive, choosing the right adhesive is often complicated by the wide variety of options available, (h) most industrial adhesives are not stable at high temperatures, oxidation reactions are accelerated, thermoplastics can soften and melt, and thermosets decompose, (i) high-strength adhesives are often brittle (poor impact properties), adhesive bond toughness may be significantly reduced under impact loading conditions, some are exposed to brittle fracture at low temperatures, (j) long-term durability and life expectancy are difficult to predict, (k) preparation and cleaning of the surface, curing and preparation of adhesives can be very vital if good and consistent results expected to be achieved; some adhesives are quite sensitive 
to the presence of grease, oil or moisture on the surfaces that need to be bonded together; surface roughness and wetting characteristics must be controlled, (l) the adhesive bonded joint design is thickness-limited, (m) it is difficult to determine the quality of a bonded joint using traditional non-destructive techniques, although some inspection methods have been developed that give good results for certain types of joints, (n) many structural adhesives deteriorate under certain operating conditions, and this adhesive can be exposed to environmental influences that may be hostile, including ultraviolet light, ozone, acid rain (low $\mathrm{pH}$ ), moisture, and salt; therefore, the durability and reliability of the connection during long life may be questioned, (o) some adhesives contain objectionable chemicals or solvents or are produced after curing, (p) the thermal residual stresses can be generated, (q) there are concerns about the fatigue and durability behaviour of bonded joints over the expected life of the vehicle and (r) the fracture behaviour of bonded joints, especially those with dissimilar adherends (e.g., composite to metal), is not yet well understood. Because bonded joints under service conditions, which include static and dynamic loads and exposure to hostile environments such as water, gasoline, other organic solvents, etc., must be satisfactory and in many cases a combination of these conditions may be experienced.

In this study, a modified version of the Arcan sample was used to test the fracture of bonded composites, allowing the interlaminar, cohesive, and interfacial cracked specimens to be tested in the same configuration. The Arcan test specimen was originally designed for use with fiber composite materials (Arcan et al., 1978), but has been adopted by many researchers for use with isotropic materials (Sutton et al. 2000), adhesives (Hossein Abadi et al., 2020; Cognard et al., 2008; Rahmani \& Choupani, 2019), composites (El-Hajjar \& Haj-Ali 2004, Shameli \& Choupani 2016), super-alloys (Katanchi et al. 2018), and polymeric materials (Oskui et al., 2016; Haddadi et al., 2016), etc. Mixed mode interlaminar, cohesive, and interfacial fracture tests were performed to determine the fracture toughness of bonded composites. Stress intensity calibration was obtained using finite element analysis using the geometric factors method. The fracture toughness of interfacial, interlaminar and cohesive cracks under different loading cases were determined and the resulting fracture surfaces were discussed.

\section{Cohesive, interfacial, and interlaminar fracture mechanics}

Failure in bonded joints is mainly of two types, interfacial and cohesive. It occurs mainly at the geometric boundaries due to stress concentration, or due to incorrect joining to the structure, mainly due to interfacial cracking, also called bonding. Adhesive joints must be separated in the adhesive (cohesive) or inside the adherends (break between layers) as shown in Fig. 3. Failure of the adhesive interface (interfacial failure) generally indicates that the bond was not performed properly. Because bonding joints usually fail with the onset and propagation of the defect, the application of failure mechanics theories has received considerable attention, as documented by Kinloch (1987). To crack in the center of a layer of adhesive that is completely away from any interface, it can be assumed to be a homogeneous material, and Irwin solution can be used around the crack in a homogeneous material. Often, cracks are created in the interface between two materials or a bond joint. Defects in composite materials are mainly due to interlaminar fracture, also called delamination. Determining the resistance to delamination is very important, because composite materials have superior properties only in the direction of the fibers.
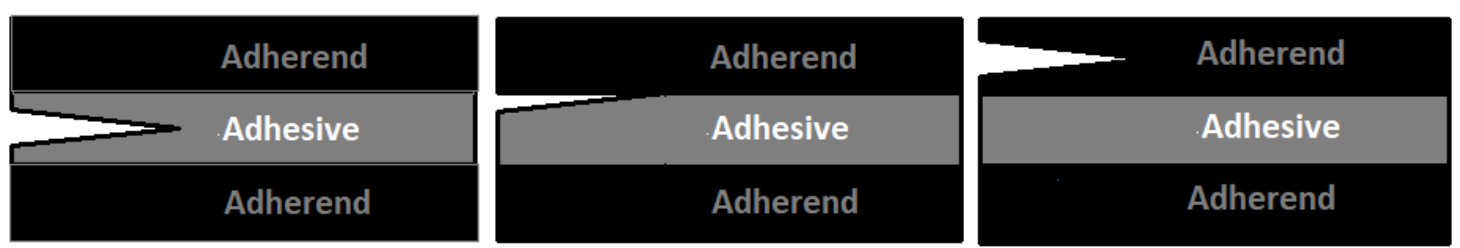

Fig. 3. Types of cracks in bonded composites; (a) cohesive, (b) interfacial and (c) interlaminar

For a crack in the center of a layer of adhesive that is completely away from any interface, it can be assumed to be a homogeneous material. The crack tip stress intensity factors $\left(K_{I}\right.$ and $\left.K_{I I}\right)$ are calculated for a modified version of the Arcan sample using the following equations (Hossein Abadi et al., 2020; Rahmani \& Choupani, 2019; Choupani, 2008a; Alfonso et al., 2018):

$$
K_{I}=\frac{P_{c} \sqrt{\pi a}}{w t} f_{I}\left(\frac{a}{w}\right), K_{I I}=\frac{P_{c} \sqrt{\pi a}}{w t} f_{I I}\left(\frac{a}{w}\right)
$$

where $P_{c}$ is force at the fracture, $w$ is length of the specimen, $t$ is thickness of the specimen and $a$ is length of the crack as shown in Fig. 4. $f_{I}(a / w)$ and $f_{I I}(a / w)$, are geometrical factors, which are obtained through finite element analysis of Arcan specimen in order to calculate $K_{I}$ and $K_{I I}$ stress intensity factors, respectively. For isotropic material and plane strain conditions, the energy can be calculated from the following relationships:

$$
G_{I}=\frac{K_{I}^{2}}{\bar{E}}, G_{I I}=\frac{K_{I I}^{2}}{\bar{E}}, \quad \bar{E}=\frac{E}{\left(1-v^{2}\right)},
$$

where elastic modulus is $E$, Poisson's constant is $v$, and effective modulus for plane strain condition is $\bar{E}$. Due to the mismatch between the materials on both sides of the interface, mixed-mode states produce inherently in the crack tip. The stress intensity factors in the interface crack tip calculated for the modified Arcan sample are simply the real and imaginary parts of a complex tress intensity factor $K=K_{1}+i K_{2}$ (Choupani, 2008b; Mirsayar et al., 2014; Tsokanas et al., 2020). For an interfacial crack between two dissimilar isotropic materials with Young's moduli $E_{1}$ and $E_{2}$, Poisson's ratios $v_{1}$ and $v_{2}$, shear moduli $\mu_{1}$ and $\mu_{2}$, and biomaterial constant $\beta$, the strain energy release rate for plane strain condition can be calculated as: 


$$
\begin{aligned}
G_{I} & =\frac{K_{I}^{2}}{E^{*}}, G_{I I}=\frac{K_{I I}^{2}}{E^{*}}, \frac{1}{E^{*}}=\frac{1-\beta^{2}}{2}\left(\frac{1}{\bar{E}_{1}}+\frac{1}{\bar{E}_{2}}\right) \\
\beta & =\frac{\mu_{1}\left(\kappa_{2}-1\right)-\mu_{2}\left(\kappa_{1}-1\right)}{\mu_{1}\left(\kappa_{2}+1\right)+\mu_{2}\left(\kappa_{1}+1\right)}, \quad \bar{E}=\frac{E}{\left(1-v^{2}\right)}, \quad \kappa=(3-4 v)
\end{aligned}
$$

Determining the resistance to delamination is very important, because composite materials have superior properties only in the direction of the fibres. Layering resistance is known as interlaminar or delamination failure resistance. For many composites, crack growth is due to the same type of lamination and results in a value of $G$ divided into modes I and II. For orthotropic materials with a crack that coincides with the fibre direction, and for the case in which the xy-system coincides with the principal material axes, strain energy rate for plane strain conditions can be calculated from the following equations (Ducept et al., 2000; Arcan et al., 1978; El-Hajjar \& Haj-Ali 2004; Shameli \& Choupani, 2016; Choupani, 2008c):

$$
\begin{aligned}
& G_{I}=\frac{K_{I}^{2}}{E_{I}}, G_{I I}=\frac{K_{I I}^{2}}{E_{I I}}, \quad \frac{1}{E_{I}}=\frac{b_{22}}{2}\left(2 \sqrt{b_{11} b_{22}}+2 b_{12}+b_{66}\right), \frac{1}{E_{I I}}=\frac{b_{11}}{2}\left(2 \sqrt{b_{11} b_{22}}+2 b_{12}+b_{66}\right), b_{11}= \\
& \frac{E_{x}-E_{z} v_{x z}^{2}}{E_{x}^{2}} b_{22}=\frac{E_{y}-E_{z} v_{y z}^{2}}{E_{y}^{2}}, b_{12}=-\frac{E_{y} v_{x y}+E_{z} v_{x z} v_{y z}}{E_{x} E_{y}}, b_{66}=\frac{1}{\mu_{x y}},
\end{aligned}
$$

where the terms of the plane strain constants $b_{i j}$ are defined in terms of the following nonzero entries of the orthotropic compliance matrix, $E_{I}$ and $E_{I I}$ are effective moduli, and $K_{I}$ and $K_{I I}$ are mode-I and mode-II stress intensity factors, respectively.

\section{Experimental procedures}

Experimental efforts were conducted on cohesive, interfacial and interlaminar fractures of the bonded CF / PEI composite with $\mathrm{FM}^{\circledR} 300-2$ adhesive. FM ${ }^{\circledR} 300-2$ is a high-strength modified rubber film adhesive that is widely used for bonding composite structures in aerospace bonding applications. The adhesive was processed according to the manufacturer's specifications. Adherend was a thermoplastic carbon fiber / polyethylene (CF / PEI) composite consisting of 12 plies of thickness of approximately 3 mm. Composites were prepared by hand lay up in the required number and produced using hot press. The specimens were cut with a diamond saw and machined to the required dimensions. The method of preparing the composite surface includes degreasing with methyl ethyl ketone (MEK), washing and checking for water breakage, hand abrasion with aluminum oxide abrasive papers, and cleaning for bonding. A non-stick film was placed in the middle of the adhesive layer (cohesive), the adhesive interface (interfacial) and between the central plies of composite (interlaminar) to create a starting crack. The elastic constants of composite and adhesive are summarized in Table 1. For composite material, the direction of 1 is parallel to the fiber and the directions of 2 and 3 are transverse to the fiber, while the crack direction is the same as the fiber. The loading device and the modified version of the Arcan sample are shown in Fig. 4. Load displacement curves generated by the testing machine were used to determine maximum loads

\begin{tabular}{|c|c|c|c|c|c|c|c|c|c|}
\hline Material & $\begin{array}{c}\mathrm{E}_{1} \\
{[\mathrm{GPa}]}\end{array}$ & $\begin{array}{c}\mathbf{E}_{2} \\
{[\mathrm{GPa}]}\end{array}$ & $\begin{array}{c}\mathbf{E}_{3} \\
{[\mathrm{GPa}]}\end{array}$ & $\begin{array}{c}\mathbf{G}_{12} \\
{[\mathbf{G P a}]}\end{array}$ & $\begin{array}{c}\mathbf{G}_{13} \\
{[\mathbf{G P a}]}\end{array}$ & $\begin{array}{c}\mathbf{G}_{23} \\
{[\mathbf{G P a}]}\end{array}$ & $v_{12}$ & $v_{13}$ & $v_{23}$ \\
\hline FM $^{\circledR} 300-2$ & 2.3 & 2.3 & 2.3 & 0.8 & 0.8 & 0.8 & 0.4 & 0.4 & 0.4 \\
\hline CF/PEI & 57.6 & 57.6 & 8.7 & 3.1 & 2.8 & 2.8 & 0.03 & 0.4 & 0.4 \\
\hline
\end{tabular}
in order to study the mixed-mode cohesive, interfacial and intrlaminar fracture toughness of bonded composite (Choupani 2008a,b,c).

Table 1. Elastic Properties of adhesive and adherend.

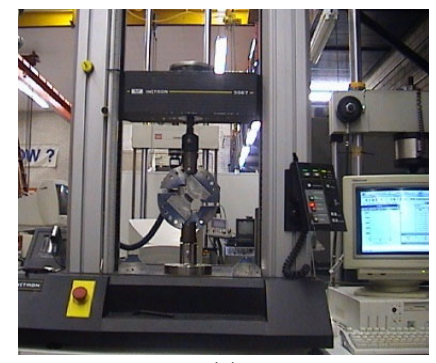

(a)

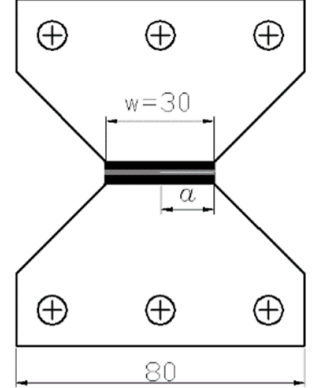

(c)

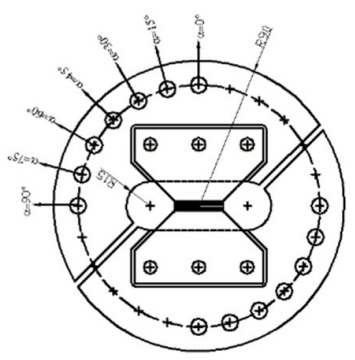

(b)

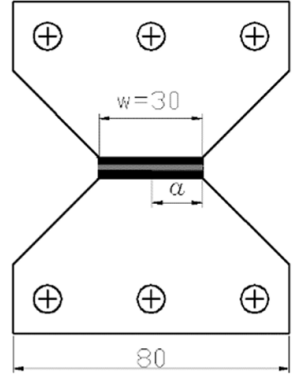

(d)

Fig. 4 (a) Arcan test specimen and loading fixture, (b) Interlaminar, (c) cohesive, and (d) interfacial crack of bonded composite 


\section{Finite element analysis}

The finite element analysis method used to calculate the geometrical factor is a J-integral interaction technique and is required to separate the components of stress intensity factors. This method can be used for cracks in isotropic and anisotropic materials. In the J-integral interaction method, two-dimensional auxiliary fields are introduced and placed on real fields. By rationally selecting auxiliary fields, the J-integral interaction can be directly related to stress intensity factors (Karlsson \& Sorensen 2001):

$$
K=4 \pi B J_{\text {int }}
$$

where $\boldsymbol{B}$ is diagonal, and $\boldsymbol{J}_{\text {int }}=\left[J_{i n i}^{I}, J_{i n i}^{I I}, J_{i n i}^{I}\right]^{T}$. In the mechanics of linear elastic fracture, the integral $J$ is equal to $J=G_{T}=$ $G_{I}+G_{I I}+G_{I I I}$, where $G_{I}, G_{I I}, G_{I I I}$ and $G_{T}$ are the tensile, shear, tear and total strain energy, respectively. Finite element analysis was performed with the ABAQUS finite element code, which directly results the components of the stress intensity factor as output. Numerical analysis was performed under plane strain conditions using root square singularity. To obtain the root square singularity from the crack tip stress field, the elements around the crack tip were concentrated on the crack tip and the middle side nodes were moved to a quarter on each side of the element. Figure 5 shows an example of a sample mesh pattern performed with the finite element code ABAQUS. The whole sample with an initial crack meshed using eight nodes of the quadrilateral element and the mesh was refined around the crack tip. In the Finite element analysis, the J-integral estimated from five rings and finite element solutions are obtained for Arcan specimens with cohesive, interfacial and intrlaminar cracks of bonded composite (ABAQUS 2001, Choupani 2008 a,b).
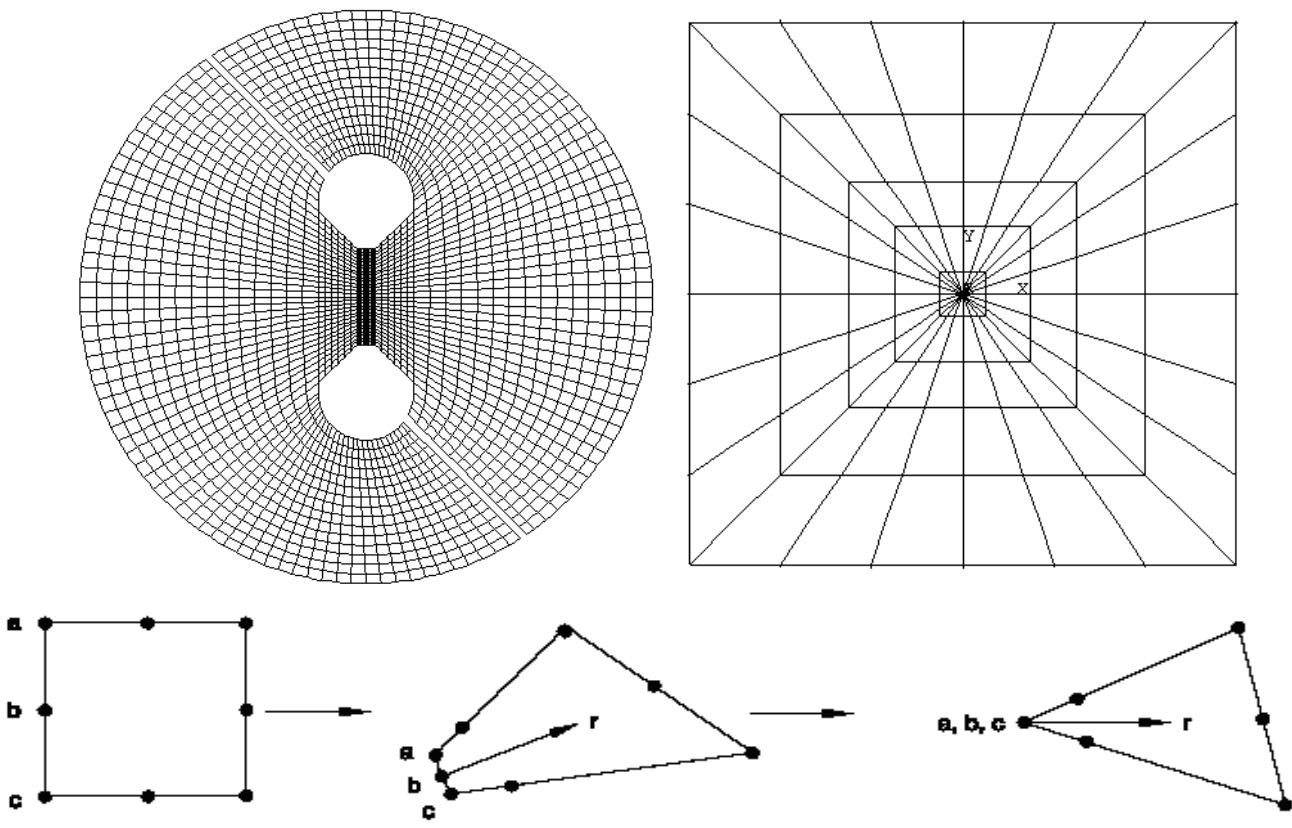

Fig. 5. Examples of the finite element model of the specimen and two-dimensional collapsed elements

\section{Results and Discussion}

In order to evaluate the stress intensity factors in different fracture modes, geometric factors were determined for cohesive, interfacial and interlaminar cracks as presented in Table 2 (Choupani 2008 a,b,c). It can be seen for all cohesive, interfacial, and interlaminar crack types that as mode-II loading contribution increases, mode-I geometry factor decreases and mode-II geometry factor increases. The type of cracks were found to have significant effects on the geometrical factors that both mode-I and modeII interlaminar crack had the maximum values among other crack types.

Table 2. Geometrical factors for cohesive, interfacial, and interlaminar cracks

\begin{tabular}{|c|c|c|c|c|c|c|c|c|}
\hline \multicolumn{2}{|c|}{ Loading Angle } & $0^{\circ}$ & $15^{\circ}$ & $30^{\circ}$ & $45^{\circ}$ & $60^{\circ}$ & $75^{\circ}$ & $90^{\circ}$ \\
\hline \multirow{2}{*}{ Interlaminar } & $f_{I}$ & 1.190 & 1.923 & 1.724 & 1.407 & 0.994 & 0.524 & - \\
\hline & $f_{I I}$ & - & 0.287 & 0.554 & 0.784 & 0.960 & 1.071 & 1.101 \\
\hline \multirow{2}{*}{ Cohesive } & $f_{I}$ & 1.150 & 1.111 & 0.996 & 0.813 & 0.575 & 0.297 & - \\
\hline & $f_{I I}$ & - & 0.123 & 0.238 & 0.336 & 0.413 & 0.459 & 0.476 \\
\hline \multirow{2}{*}{ Interfacial } & $f_{I}$ & 0.807 & 0.745 & 0.632 & 0.476 & 0.287 & 0.078 & 0.136 \\
\hline & $f_{I I}$ & 0.274 & 0.367 & 0.434 & 0.471 & 0.476 & 0.448 & 0.390 \\
\hline
\end{tabular}


The fracture test was performed by controlling the fixed displacement rate of $0.5 \mathrm{~mm} / \mathrm{min}$ and the fracture loads and displacements were recorded. The experiments were repeated 3 times for each loading angle with different types of cracks. Load displacement curves generated by the testing machine were used to determine maximum loads and displacements. For each type of crack, mode I, mode II and five mixed mode loading conditions are used as in Table 3 (Choupani 2008 a,b,c).

Table 3. Cohesive, interfacial and interlaminal fracture loads $P_{C}[\mathrm{~N}]$ under different loading angles

\begin{tabular}{|c|c|c|c|c|c|c|c|c|}
\hline Loading Angl & & $0^{\circ}$ & $15^{\circ}$ & $30^{\circ}$ & $45^{\circ}$ & $60^{\circ}$ & $75^{\circ}$ & $90^{\circ}$ \\
\hline \multirow{4}{*}{ Interlaminar } & 1 & 2023 & 2137 & 2216 & 2640 & 3490 & 4936 & 6776 \\
\hline & 2 & 1813 & 1851 & 2102 & 2606 & 3201 & 4895 & 6285 \\
\hline & 3 & 1702 & 1746 & 1884 & 2320 & 3114 & 4369 & 6282 \\
\hline & Avg. & 1846 & 1911 & 2067 & 2522 & 3269 & 4734 & 6448 \\
\hline \multirow{4}{*}{ Cohesive } & 1 & 985 & 918 & 1098 & 1190 & 1500 & 2066 & 2583 \\
\hline & 2 & 734 & 771 & 856 & 1070 & 1489 & 1943 & 2496 \\
\hline & 3 & 626 & 711 & 735 & 881 & 1272 & 1774 & 1944 \\
\hline & Avg. & 782 & 800 & 896 & 1047 & 1420 & 1928 & 2341 \\
\hline \multirow{4}{*}{ Interfacial } & 1 & 666 & 695 & 795 & 1024 & 1214 & 1700 & 2144 \\
\hline & 2 & 675 & 705 & 749 & 896 & 1182 & 1714 & 2120 \\
\hline & 3 & 645 & 680 & 736 & 766 & 1065 & 1566 & 1969 \\
\hline & Avg. & 662 & 693 & 760 & 895 & 1154 & 1660 & 2078 \\
\hline
\end{tabular}

Cohesive, interfacial and interlaminar fracture toughness values were derived from the fracture loads and geometrical factors. Table 3 summarizes the mean values of experimentally determined fracture toughness under various loading conditions as reported in (Choupani, $2008 \mathrm{a}, \mathrm{b}, \mathrm{c}$ ). The tensile mode fracture toughness decreases and the shear mode fracture toughness increases as the shear mode loading contribution, (i.e. as $\alpha$ angle increases); this is true for all three crack types (cohesive, interfacial, and interlaminar cracks) studied. Fracture toughness measurements for the modified Arcan specimen under pure mode-I loading show the average fracture toughness of $K_{I C}=2.658\left[\mathrm{MPa} \mathrm{m}^{1 / 2}\right]$ for interlaminar crack, $K_{I C}=0.651\left[\mathrm{MPa} \mathrm{m}{ }^{1 / 2}\right]$ for cohesive crack and $K_{I C}$ $=0.386\left[\mathrm{MPa} \mathrm{m}^{1 / 2}\right]$ for interfacial crack. For pure mode-II loading using modified Arcan specimen, the average fracture toughness for interlaminar crack $K_{I I C}=5.174\left[\mathrm{MPa} \mathrm{m}^{1 / 2}\right]$, for cohesive crack $\mathrm{K}_{I I C}=0.806\left[\mathrm{MPa} \mathrm{m}^{1 / 2}\right]$ and for interfacial crack $K_{I I C}=0.586$ $\left[\mathrm{MPa} \mathrm{m}^{1 / 2}\right]$.

Table 4. Average cohesive, interfacial and interlaminar fracture toughness data $(K)_{C}\left[\mathrm{MPa} \mathrm{m}{ }^{1 / 2}\right]$ for different loading angles

\begin{tabular}{|c|c|c|c|c|c|c|c|c|}
\hline \multicolumn{2}{|c|}{ Loading Angle ( $\alpha$ ) } & $\mathbf{0}^{\circ}$ & $15^{\circ}$ & $30^{\circ}$ & $45^{\circ}$ & $60^{\circ}$ & $75^{\circ}$ & $90^{\circ}$ \\
\hline \multirow{2}{*}{ Interlaminar } & $K_{I C}$ & 2.658 & 2.659 & 2.578 & 2.568 & 2.352 & 1.761 & - \\
\hline & $K_{I I C}$ & - & 0.397 & 0.829 & 1.430 & 2.271 & 3.668 & 5.174 \\
\hline \multirow{2}{*}{ Cohesive } & $K_{I C}$ & 0.651 & 0.643 & 0.646 & 0.616 & 0.591 & 0.414 & - \\
\hline & $K_{I I C}$ & - & 0.071 & 0.154 & 0.255 & 0.424 & 0.641 & 0.806 \\
\hline \multirow{2}{*}{ Interfacial } & $K_{I C}$ & 0.386 & 0.374 & 0.348 & 0.308 & 0.240 & 0.094 & - \\
\hline & $K_{I I C}$ & 0.131 & 0.184 & 0.239 & 0.305 & 0.397 & 0.538 & 0.586 \\
\hline
\end{tabular}

Calculated values of critical strain energy values $\left(G_{C}\right)$ are indication of bond durability by quantifying the amount of energy required to create failure levels. Table 5 shows $G_{I C}, G_{I I C}$ and $G_{T C}=G_{I C}+G_{I I C}$, which was obtained using experimental data for interlaminar, cohesive and interfacial cracks at different loading angles as reported in (Choupani 2008a,b,c). The relationship between fracture toughness of all crack types was $G_{I C}<G_{\text {mixedC }}<G_{I I C}$ under any loading conditions. Pure mode-I and pure modeII fracture toughness of interlaminar crack specimens were approximately $G_{I C}=787.8 \mathrm{~J} / \mathrm{m}^{2}$ and $G_{I I C}=1159.8 \mathrm{~J} / \mathrm{m}^{2}$, respectively. The fracture surfaces of interlaminar cracked specimen are indicative of a brittle cleavage fracture with reasonably smooth and flat matrix failure and shows debonding between fiber and matrix (Fig. 6a). The type of fracture surface displayed by the cohesive cracks resulted in lower fracture toughness values than exhibited by the interlaminar crack system. Pure mode-I and pure mode-II fracture toughness of the cohesive crack systems were $G_{I C}=153.2 \mathrm{~J} / \mathrm{m}^{2}$ and $G_{I I C}=235.3 \mathrm{~J} / \mathrm{m}^{2}$, respectively. In the fracture path of cohesive crack system, the crack appeared to occur in the composite and adhesive interface, in which the cohesive failure of adhesive with evidence of cavities can be seen (Fig. 6b). However, in general, the interfacial cracks exhibited the lowest fracture toughness properties under all modes of loading conditions. This was due to the apparent fracture surface of the interfacial crack system through which the fracture appeared to grow. Pure mode-I and pure mode-II fracture toughness of the interfacial cracks were $G_{I C}=30.4 \mathrm{~J} / \mathrm{m}^{2}$ and $G_{I I C}=62.8 \mathrm{~J} / \mathrm{m}^{2}$, respectively. SEM fracture surface observations of bonded composite interfacial crack indicate that the fracture mode was always interfacial in all cases (at the adhesive / composite interface). The fracture path was generally in the interface of matrix layer of the composite near the adhesive / composite interface, and evidence of adhesive particle removal and cavities is visible after fracture (Fig. 6c). 
Table 5. Average cohesive, interfacial and interlaminar values of critical strain energy $G_{C}\left[\mathrm{~J} / \mathrm{m}^{2}\right]$ for different loading angles

\begin{tabular}{|c|c|c|c|c|c|c|c|c|}
\hline \multicolumn{2}{|c|}{ Loading Angle $(\alpha)$} & $0^{\circ}$ & $15^{\circ}$ & $30^{\circ}$ & $45^{\circ}$ & $60^{\circ}$ & $75^{\circ}$ & $90^{\circ}$ \\
\hline \multirow{3}{*}{ Interlaminar } & $\overline{G_{I C}}$ & 787.8 & 788.1 & 741.0 & 735.0 & 616.9 & 345.8 & - \\
\hline & $\boldsymbol{G}_{I I C}$ & - & 6.8 & 29.8 & 88.7 & 223.5 & 583.1 & 1159.8 \\
\hline & $\boldsymbol{G}_{T C}$ & 787.8 & 794.9 & 770.8 & 823.7 & 840.4 & 928.9 & 1159.8 \\
\hline \multirow{3}{*}{ Cohesive } & $G_{I C}$ & 153.2 & 149.6 & 151 & 137.3 & 126.3 & 62.2 & - \\
\hline & $G_{I I C}$ & - & 1.8 & 8.6 & 23.5 & 65 & 148.9 & 235.3 \\
\hline & $\boldsymbol{G}_{T C}$ & 153.2 & 151.5 & 159.7 & 160.8 & 191.2 & 211.1 & 235.3 \\
\hline \multirow{3}{*}{ Interfacial } & GIC & 27.3 & 25.6 & 22.2 & 17.4 & 10.5 & 1.6 & - \\
\hline & GIIC & 3.1 & 6.2 & 10.4 & 17.0 & 28.8 & 53.0 & 62.8 \\
\hline & $\boldsymbol{G}_{T C}$ & 30.4 & 31.8 & 32.6 & 34.4 & 39.3 & 54.6 & 62.8 \\
\hline
\end{tabular}

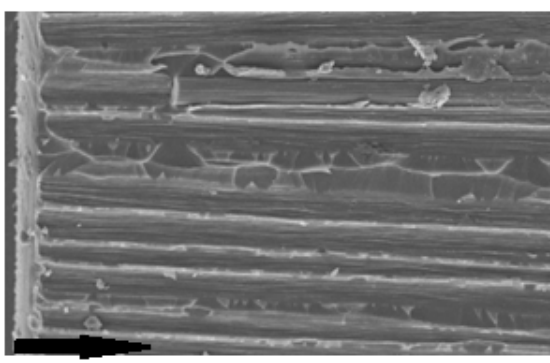

(a)

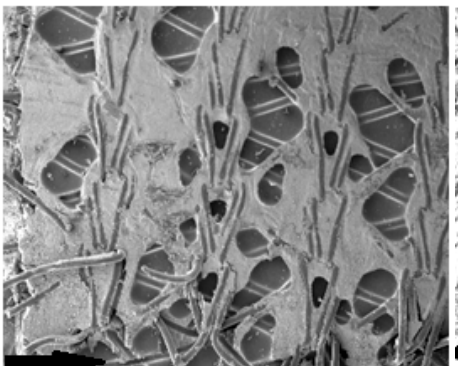

(b)

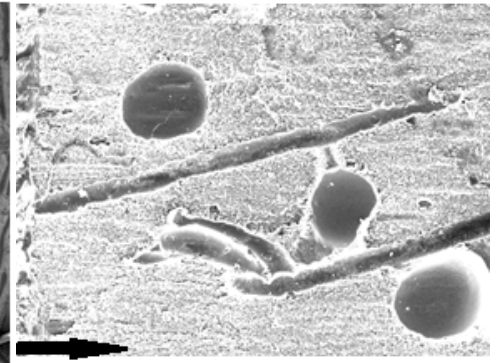

(c)

Fig. 6. SEM micrograph of (a) interlaminar, (b) cohesive, and (c) interfacial cracked bonded composite system.

\section{Conclusions}

In this study the mixed-mode fracture behavior for bonded composites constructed of interlaminar, cohesive, and interfacial crack system was investigated based on experimental and numerical analyses. A modified version of Arcan specimen was employed to conduct mixed-mode test using the special test loading device. The results of fracture toughness tests revealed that the interlaminar crack system was strong to the cohesive and interfacial crack system under all loading conditions. The SEM fracture surfaces observations showed that the interlaminar fracture surface is indicative of a brittle cleavage failure with relatively smooth and flat matrix fracture and shows debonding between fiber and matrix. Results of bonded composites with cohesive crack system showed lower fracture toughness than interlaminar crack system under all modes of loading. Fracture in the bonded composite with cohesive crack was interfacial with a small number of debonded adhesive particles embedded in the adherend side and evidence of cavities on the adhesive side. The result of fracture toughness tests revealed that the interfacial fracture of bonded composites was the weakest among other crack systems under all loading conditions. The observed crack paths of interfacial crack system adhesive with the crack running parallel to the interface.

\section{References}

ABAQUS (2001), Hibbit, H. D., Karlsson, B. I., \& Sorensen, K. (2001). ABAQUS user's and theory manuals, version 6.2. Hibbitt, Karlsson, and Sorensen Inc., Pawtucket, RI.

Alfonso, L., Badulescu, C., \& Carrere, N. (2018). Use of the modified Arcan fixture to study the strength of bonded assemblies for automotive applications. International Journal of Adhesion and Adhesives, 80, 104-114.

Aliha, M. R. M., Kucheki, H. G., \& Mirsayar, M. (2021). Mixed Mode I/II Fracture Analysis of Bi-Material Adhesive Bonded Joints Using a Novel Short Beam Specimen. Applied Sciences, 11(11), 5232.

Arcan, M., Hashin, Z. A., \& Voloshin, A. (1978). A method to produce uniform plane-stress states with applications to fiberreinforced materials. Experimental mechanics, 18(4), 141-146.

Baker, A. (1999). Bonded composite repair of fatigue-cracked primary aircraft structure. Composite structures, 47(1-4), $431-443$.

Baldan, A. (2004). Adhesively-bonded joints in metallic alloys, polymers and composite materials: Mechanical and environmental durability performance. Journal of Materials Science, 39(15), 4729-4797.

Choupani, N. (2008a). Experimental and numerical investigation of the mixed-mode delamination in Arcan laminated specimens. Materials Science and Engineering: A, 478(1-2), 229-242.

Choupani, N. (2008b). Interfacial mixed-mode fracture characterization of adhesively bonded joints. International Journal of Adhesion and Adhesives, 28(6), 267-282. 
Choupani, N. (2008c). Mixed-mode cohesive fracture of adhesive joints: Experimental and numerical studies. Engineering fracture mechanics, 75(15), 4363-4382.

Cognard, J. Y., Créac'hcadec, R., Sohier, L., \& Davies, P. (2008). Analysis of the nonlinear behavior of adhesives in bonded assemblies - Comparison of TAST and Arcan tests. International Journal of Adhesion and Adhesives, 28(8), 393-404.

Ducept, F. D. P. G. D., Davies, P., \& Gamby, D. (2000). Mixed mode failure criteria for a glass/epoxy composite and an adhesively bonded composite/composite joint. International Journal of Adhesion and Adhesives, 20(3), 233-244.

El-Hajjar, R., \& Haj-Ali, R. (2004). In-plane shear testing of thick-section pultruded FRP composites using a modified Arcan fixture. Composites Part B: Engineering, 35(5), 421-428.

Galińska, A., \& Galiński, C. (2020). Mechanical Joining of Fibre Reinforced Polymer Composites to Metals-A Review. Part II: Riveting, Clinching, Non-Adhesive Form-Locked Joints, Pin and Loop Joining. Polymers, 12(8), 1681.

Higgins, A. (2000). Adhesive bonding of aircraft structures. International Journal of Adhesion and Adhesives, 20(5), 367-376.

Hossein Abadi, R., Refah Torun, A., Mohammadali Zadeh Fard, A., \& Choupani, N. (2020). Fracture characteristics of mixedmode toughness of dissimilar adherends (cohesive and interfacial fracture). Journal of Adhesion Science and Technology, 34(6), 599-615.

Katanchi, B., Choupani, N., Khalil-Allafi, J., Tavangar, R., \& Baghani, M. (2018). Mixed-mode fracture of a superelastic NiTi alloy: Experimental and numerical investigations. Engineering Fracture Mechanics, 190, 273-287.

Khajedezfouli, M., Choupani, N., Torun, A. R., \& Yengejeh, E. A. (2020). Fracture assessment of pipeline girth weld at low temperature. Journal of the Brazilian Society of Mechanical Sciences and Engineering, 42(12), 1-11.

Kinloch, A. J. (1987). Adhesion and adhesives: science and technology. Chapman and Hall.

Mirsayar, M. M., Aliha, M. R. M., \& Samaei, A. T. (2014). On fracture initiation angle near bi-material notches-Effects of first non-singular stress term. Engineering fracture mechanics, 119, 124-131.

Oskui, A. E. H., Choupani, N., \& Shameli, M. (2016). 3D characterization of mixed-mode fracture toughness of materials using a new loading device. Latin American Journal of Solids and Structures, 13, 1464-1482. Haddadi, E., Choupani, N., \& Abbasi, F. (2016). Experimental investigation on the mixed-mode fracture of rubber-toughened PMMA using essential work of fracture method. Engineering Fracture Mechanics, 162, 112-120.

Rahmani, A., \& Choupani, N. (2019). Experimental and numerical analysis of fracture parameters of adhesively bonded joints at low temperatures. Engineering Fracture Mechanics, 207, 222-236.

Santos, M. A. S., \& Campilho, R. D. S. G. (2017). Mixed-mode fracture analysis of composite bonded joints considering adhesives of different ductility. International Journal of Fracture, 207(1), 55-71.

Shameli, M., \& Choupani, N. (2016). Fracture criterion of woven glass-epoxy composite using a new modified mixed-mode loading fixture. International Journal of Applied Mechanics, 8(02), 1650015.

Sutton, M. A., Deng, X., Ma, F., Newman Jr, J. C., \& James, M. (2000). Development and application of a crack tip opening displacement-based mixed mode fracture criterion. International Journal of Solids and Structures, 37(26), 3591-3618.

Tserpes, K. (2020). Adhesive bonding of aircraft structures. Revolutionizing Aircraft Materials and Processes, $337-357$.

Tsokanas, P., Loutas, T., \& Nijhuis, P. (2020). Interfacial Fracture Toughness Assessment of a New Titanium-CFRP Adhesive Joint: An Experimental Comparative Study. Metals, 10(5), 699.

Yengejeh, E. A., Torun, A. R., Khajedezfouli, M., \& Choupani, N. (2020). Fracture Toughness Assessment of Longitudinally Seam-Welded Gas Pipelines at Low Temperatures. Journal of Pipeline Systems Engineering and Practice, 11(4), 04020049.

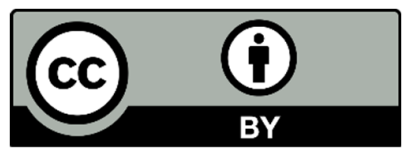

(C) 2022 by the authors; licensee Growing Science, Canada. This is an open access article distributed under the terms and conditions of the Creative Commons Attribution (CC-BY) license (http://creativecommons.org/licenses/by/4.0/). 